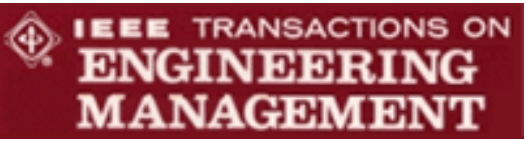

\title{
Facility Selection Model for BOPS Service for an Omni- Channel Retail Chain
}

\begin{tabular}{|r|l|}
\hline Journal: & Transactions on Engineering Management \\
\hline Manuscript ID & TEM-20-0066.R1 \\
\hline Manuscript Type: & Research Article \\
\hline Keywords: & $\begin{array}{l}\text { Location Selection, Analytical Hierarchy/Network Process, Location } \\
\text { analysis., Location/distribution, Multicriteria and Multiobjective Decision } \\
\text { Making, Supply Chain Integration }\end{array}$ \\
\hline Subject Category: & Manufacturing and Supply Chain Systems \\
\hline
\end{tabular}

\section{SCHOLARONE \\ Manuscripts}




\title{
Facility Selection Model for BOPS Service for an Omni-Channel Retail Chain
}

\begin{abstract}
Retail sector around the world is going through a transition due to digitalization. Customers now demand convenience of online channel with instant fulfilment of offline channel. As a result, the concept of omni-channel retailing has come into existence. In omni-channel retailing, both the channels of a firm are fully or partially integrated. There are many strategies that may be developed by retailers for efficient functioning of the omni-channel retail chain. The choice of such a strategy depends upon the comparative benefits that can be derived from them. One such strategy gaining immense attention of retailers is the Buy Online Pickup in Store (BOPS) strategy. In order to understand this BOPS, we conducted a detail case study of an Indian multi-channel retail chain who is considering the option of launching BOPS option in few of its retail stores. The focus is to evaluate and select a fixed number of operational retail stores to also act as pick-up points for online deliveries. $K$-means clustering is utilized for formation of retail zones as per the number of retail stores to be selected. The retail stores in each zone are evaluated on the basis of a number of criteria such as demand, inventory carrying capacity, cost, and population characteristics using Analytical Hierarchy Process (AHP) and Complex Proportional Assessment-Grey (COPRAS-G). Based on these evaluations the best suitable retail store is selected for expansion from each zone. The result implications drawn in the study can provide an understanding of the future strategies that can be developed by the decision makers of the firm for launching the BOPS option. The study can also be beneficial to other Indian retail firms who can derive meaningful insights from the findings.
\end{abstract}

Index Terms - AHP-COPRAS-G, BOPS, Omni-channel Retailing, Location Selection, BOPS

\section{INTRODUCTION}

$I^{\mathrm{r}}$ $\mathrm{N}$ recent years there has been a significant change in the retail sector all over the world. Increasing reach of online channel and rising digitalization has changed the purchasing behavior of customers [1]-[3]. Retail firms are now offering products at both online as well as bricks and mortar stores [4]. Traditional retail firms are adding an additional online channel to their channel mix and online retail firms are opening their bricks and mortar stores themselves or in collaboration with other firms [5]. Thus, a huge number of retail firms have adopted Multi-Channel (MC) approach of retailing [6]. However, these channels operate independently (of the same firm) and often compete with each other [7]. As a result, supply chains of the retail firms are now fragmented and it becomes difficult for them to provide superior customer experience [5]. To overcome these drawbacks of MC retailing, retail firms have started integrating their channels which has given rise to Omni-Channel (OC) retailing. In OC retailing, different channels of the retail firm operate in an integrated manner and customers can switch between the channels easily [5]. It is a holistic approach to retailing in which all the channels are capitalized as customer touchpoints [8]. Thus, MC retail firms all over the world are now focused upon achieving this integration amongst their different channels. For instance, brands such as Van Heusen, Pepperfry, Raymond's, and Zivame have launched their digitally immersive flagship stores in India and Adidas has introduced a technology called endless-aisle technology in its retail stores as part of their OC strategy [9].

Earlier the retail firms were focused upon deciding which channel should be used for their product(s) and whether they should venture into MC retailing or not. However, their focus has now shifted towards understanding how they can integrate and manage their multiple channels efficiently to provide satisfactory customer experience [10]. In this regard, the challenge faced by the retail firms in integrating their online and offline channels is the difference between the two in terms of delivery of information regarding the product and the way in which product fulfilment is performed [11]. Nevertheless, despite the challenges in OC retailing, retail firms have options of various combinations for information delivery and product fulfilment, which introduces new opportunities. Reference [12] represented these combinations in the form of an information fulfilment matrix, based on which a number of OC strategies are being adopted by the retail firms. For instance, retail firms like Oasis, REI, Timberland, Orvis, VIP.com, Sephora, and many more have become world leaders in implementing OC strategy by synergizing both their online and offline channels. However, in countries like India, retail firms are still struggling with the identification of best OC strategy and its effective implementation. Reference [13] conducted a survey to identify which strategy for OC retailing is of highest priority for MC retail firms in Europe and USA based on which it was concluded that Buy-Online-Pickup-in-Store (BOPS) has strategic priority for MC retail firms all over the world [14].

Under BOPS, the customers can buy the desired product online and can pick the product themselves from the nearby pickup point. Amazon was the first retail firm to launch in-store pickup service in India in 2014 [15]. After observing the success of Amazon's in-store pickup service, a number of other retail firms in India like Flipkart, DMart, Reliance Retail, Croma, Lifestyle, etc. have also launched this service [16]-[18]. Customers' nowadays want absolute guarantee of product availability when they visit the store, instantaneous picking and tracking, and to pay for their purchase when they pick their orders [13]. BOPS option permits the customers to reap the benefits of both the channels. They can explore and buy the product online and can get it instantly 
which leads to reduced waiting time and saves shipping fee [19]. Moreover, customers enjoy the benefit of hassle-free shopping experience at retail store as their items are already packed when they arrive [14]. Implementing BOPS is not only beneficial for customers but also for the retail firms [3]. BOPS boosts store traffic which leads to increased sales. Moreover, customers visiting the retail stores for picking up their order may buy some additional products during their visit [20], [21]. Introduction of BOPS also increases the environment friendliness of the supply chain as it alleviates traffic congestion [22]. Thus, to reap these benefits of BOPS, a number of MC retail firms in India are planning to launch BOPS option for their customers [23].

However, the key challenge of Indian retail firms is to re-configure their supply chains for adopting BOPS strategy which includes the selection of the right set of retail stores to be expanded as pick-up points for online orders. Most retailers agree that adopting an all-inclusive strategy of expanding all their retail stores to act as pick-up locations for BOPS orders may not be beneficial [24]. One of the other major reasons for being selective is inadequate inventory carrying capacity of retail store, which can act as a barrier in order fulfilment and may lead to stock-outs and consequently affecting walk-in customers' shopping experience [13], [25]. Moreover, BOPS option requires manual operations, thus, insufficient staffing levels at the retail store may lead to untimely delivery of BOPS orders and also hinder offline customers [26]. Therefore, launching the BOPS option may affect the performance of both the online as well as offline channels of the firm. As highlighted earlier, the efficient working of a retail store as a pickup point depends upon a number of conflicting factors like store characteristics which include inventory carrying capacity of the store, availability of staff, accessibility of retail store; population structure near the retail store; and a number of other factors [24], [27], [28]. Moreover, the decision of selection of retail store as pick up point is strategic in nature which may affect other supply chain decisions immensely and must be made in consensus with all the Decision Makers (DMs) of the company. Clearly, there is a need for Multi-Criteria Decision Making (MCDM) for selecting the best suitable retail stores to be expanded as pick-up points. However, there is limited research that addresses how MC retail firms can launch BOPS service, and none of the studies have developed mathematical framework for guiding retail firms in determining the number of retail stores to be expanded as pickup points and selecting them from the ones available.

Hence, with this context of MC retail firms moving towards OC retailing by launching BOPS option, this research considers an important decision that can help these retail firms in attaining efficient and effective customer service at lower costs. With this motivation, we have developed an analytical framework for helping MC retail firms in India, taking a particular case of an apparel retail chain, in identifying a subset of their retail stores which can act as pickup locations for BOPS orders. The key objectives to achieve the purpose are:

- To identify the attributes for evaluation of retail stores based on customers' expectation and firm's capabilities for selection in OC retailing.

- To develop an MCDM based mathematical model for the evaluation and selection of retail stores based on selected attributes in each demand zone.

The problem of retail store selection as pick up points is a MCDM problem as it is influenced by many tangible criteria (like operational cost, expansion cost, inventory carrying cost, etc.) and intangible criteria (like accessibility of retail store, expansion possibility of retail store, population characteristics and so on) and the firms have to consider the economic and practical feasibility of expansion which can be done with the help of a number of experts like retail operations manager, marketing manager, financial advisor, and so on [29]. Therefore, the present study aims to achieve the above objectives by developing an integrated MCDM model to help an Indian MC retail firm to evaluate and select its retail stores for expansion as pickup points for BOPS orders. Initially, the firm's existing retail stores are clustered into a fixed number of retail zones using $K$-means clustering. A literature survey is carried out to identify the criteria for evaluation. The identified criteria are prioritized based on DMs' preferences using Analytical Hierarchy Process (AHP) in order to obtain their weights of importance. The retail stores in each cluster are then evaluated using the identified criteria with the help of Complex Proportional Assessment-Grey (COPRAS-G) method and the best ranked retail store from each retail zone is selected for expansion.

The originality of this study which distinguishes it from other studies in this field lies in development of a novel integrated model for an Indian MC retail firm which can aid the firm in evaluation of retail stores based on an exhaustive list of criteria for expansion as pickup points. The remainder of the article is organized as follows: section two presents the literature review on the work done in the field of OC retailing and specifically related to BOPS strategy. The case problem under study is described in section three. The proposed methodology for selection of retail stores is presented in section four. The analytical framework is numerically validated and the results are presented in section five. Theoretical and managerial implications are presented in section six and section seven concludes the study by highlighting the future scope.

\section{LITERATURE REVIEW}

There are various challenges faced by retailers while implementing OC retailing. Some of these include the following: marketing-related barriers [8], [30] which correspond to problems related to product assortment [8], [12] and inconsistency of product lines and prices [12], [31]; supply chain and logistics related barriers [32], [33] such as inability to establish a unified information system [32], [34] and inability to leverage on integrated processes [8], [10]; organizational management related barriers [34] which include competitiveness [35] and intra-organizational resistance [36]. On the other hand, apart from these challenges, 
OC retailing presents a number of opportunities such as enhanced customer service [12], [33], expanded market share [32], increased product promotion and price transparency [33], [37], and infusion of business innovation [8], [36]. To capitalize on these opportunities, the SC managers must focus on choosing the right OC strategy and re-configuration of the supply chain network and related logistics activities accordingly [38].

There are many studies which have worked on the selection of OC retailing strategies [12], [13], [36], [38]. The decision of adoption of OC retailing strategy is predominantly influenced by customers' numerous requirements and varied profile [21], [39], [40]. Furthermore, customers' channel selection decision generally depends upon two types of factors; factors in control of the company such as available channel information, channel convenience, channel price advantage, etc. and factors such as customers' previous shopping experience, their impulsiveness, need for touch, perception, and attractiveness [3], [39], [40]. Therefore, to amalgamate all these varied channel characteristics and customer preferences, strategies like cross-channel inventory availability information, new delivery modes like in store pickup, and into the store returns can be beneficial for retailers [21]. In a study conducted by [14], authors have assessed that BOPS option is beneficial for customers in two ways: it provides real time knowledge about inventory availability at the retail store and it reduces the hassle cost of shopping. In terms of the retailers too, study by [39] concludes that hybrid strategies like BOPS can be extremely beneficial for OC retailers. To understand the various scenarios under which BOPS strategy can work for retailers in a competitive market, the reader can refer to [41].

In the survey conducted by [13] on OC retail firms in US and Europe, the author found that providing store pickup service has become a must for customers and OC retailers are focusing on the execution of BOPS strategy effectively. As a result, many researchers have conducted various empirical studies to understand and analyze the strategies for implementation of BOPS. Reference [3] have conducted a survey in USA to understand how customers' intention to use BOPS is affected by the innovation characteristics and perceived risk associated with online shopping. The analysis was done taking into account the effects of situational factors like location convenience and the product type. Reference [20] have analyzed the impact of BOPS implementation in USA in terms of cross-selling effect and channel-shift effect. The impact is analyzed based on the cart abandonment rate for both the channels. Reference [42] recommended that to fulfil both traditional and BOPS orders at the retail store in China, unit inventory carrying cost and the arrival rate of customers for collecting BOPS orders, both play important roles in determining the size of service area. It can be observed from the above discussion that there have been various empirical studies related to OC retailing in countries like US, UK, and Europe. However, similar studies focusing on adoption of OC retailing in emerging economies like India are scant.

Apart from empirical studies, a number of researchers have developed mathematical models for effective implementation of BOPS strategy. For instance, [43] have developed mathematical models to study the BOPS strategy with pre-orders for a retailer in the presence of informed and uninformed customers. Reference [44] have identified the conditions under which dual-channel retailers should adopt this strategy using mathematical models. Reference [44] have assessed the impact of introducing BOPS service on the sales and returns of both online and offline channels for a U.S. based jewelry retailer. Reference [25] have developed a mathematical model for determining the minimum picking rate needed in stores for achieving desired service level and the optimal number and timings of picking waves the retailer should execute in an ordering cycle for fulfilling BOPS orders. Reference [22] have developed a stylized model to identify the conditions when uniform pricing strategy and BOPS strategy might dominate. The location of pickup points for collecting BOPS orders plays an important role in the success of this strategy. There is limited research related to the identification of location for pickup points for BOPS orders in OC retailing. Reference [24] have developed a mathematical model for specifying which retail store should be presented to online customer at the time of checkout for order picking. Customers' preferences are modelled for a retail store based on the geographical location. Reference [27] have studied the spatiotemporal location problem in an OC environment. In their study, demand is predicted at some potential locations for pickup points for BOPS orders based on demographic, economic, business location, historical sales, and operations data using a number of machine learning techniques. Based on the predicted demand, a mathematical model is developed to determine the optimal pickup location configuration and schedule for their trucks. It can be observed that none of the above-mentioned studies have developed an exhaustive evaluation process prior to the selection of pickup points. Additionally, to the best of our knowledge, integration of essential attributes such as operational and expansion cost of the retail store, scope of expansion of the store, workforce availability and so on have not been considered together with the attributes corresponding to BOPS facility location in any of the previous studies as has been done in this study. Moreover, since the location selection problem is dependent on a number of criteria, it is an MCDM problem. Nonetheless, the evaluation and selection of retail stores based on a set of criteria using integrated MCDM models as done in this study has never been done before.

Thus, the above highlighted research gap brings forth the following research contributions of this study:

- In the research related to OC retailing, a number of studies exist that address the issues related to OC retailing in developed countries like US, UK, Europe, and China. However, in this paper the focus is on the implementation of OC retailing in emerging economies like India. In this paper we have considered the case of an Indian apparel retail firm for developing a framework for pickup location selection for BOPS orders.

- Identification of set of criteria for the selection of location of retail stores is imperative for effective decision making. Thus, in this study we have identified an exhaustive list of criteria for the selection of a retail store to function as pickup location for collecting BOPS orders. The basis for identification of majority of the criteria is specifically related to 
customer preferences, their demographics, and convenience. Additionally, a number of traditional criteria of location selection decision making like cost, availability, and so on have also been considered. In contrast, most existing studies on selection of retail stores have not considered such specific customer-centric criteria as they have not studied the problem of expansion of existing retail stores to act as pickup points for BOPS orders.

- The most noteworthy contribution of the paper is development of an integrated MCDM model for evaluation and selection of pick up points. First, the retail zones are identified using $K$-means clustering. Secondly, the importance ratings of criteria are identified using AHP. Finally, to select a retail store in each zone, we have used COPRAS-G method to prioritize each retail store based on the criteria and their importance ratings.

\section{CASE PROBLEM}

This section presents the case of a leading Indian MC apparel retail firm XYZ (name not disclosed due to reasons of confidentiality) which is inclined towards OC retailing. The firm is a leader in ethnic women clothing segment and has an annual turnover of INR 300 crores. Its product portfolio includes everyday wear, work wear, casual wear, and festive wear clothing for women. With market for women's ethic apparel growing rapidly in India and increasing competition day by day, it is imperative for XYZ to always keep implementing innovative strategies to attract customers. The firm is a market leader in terms of product development, manufacturing, and sourcing. The efficient supply chain management practices of the firm differentiate it from its competitors.

The product development process of the firm utilizes in-depth market survey and data analysis. Since women's ethnic wear requires a wide range of fabric and other material, therefore the firm has developed an extensive procurement network for sourcing the raw material. It has built a long-term relationship with its suppliers which ensures quality and timely product delivery to its customers. For selling the products, well established offline as well as online channels are operational which cater to the customer demand from all over India. Fig. 1 illustrates the supply chain network of the retail firm. Currently, there are dedicated central warehouses for online and offline modes of product fulfilment. The products for offline mode are transported to retail stores from the central warehouse for offline orders based on retailers' demand. Offline demand is satisfied through these retail stores. The online orders are packed at the central warehouse dedicated to cater online orders. These packed orders are transported to regional warehouses from the central warehouse and delivered to the final customers.

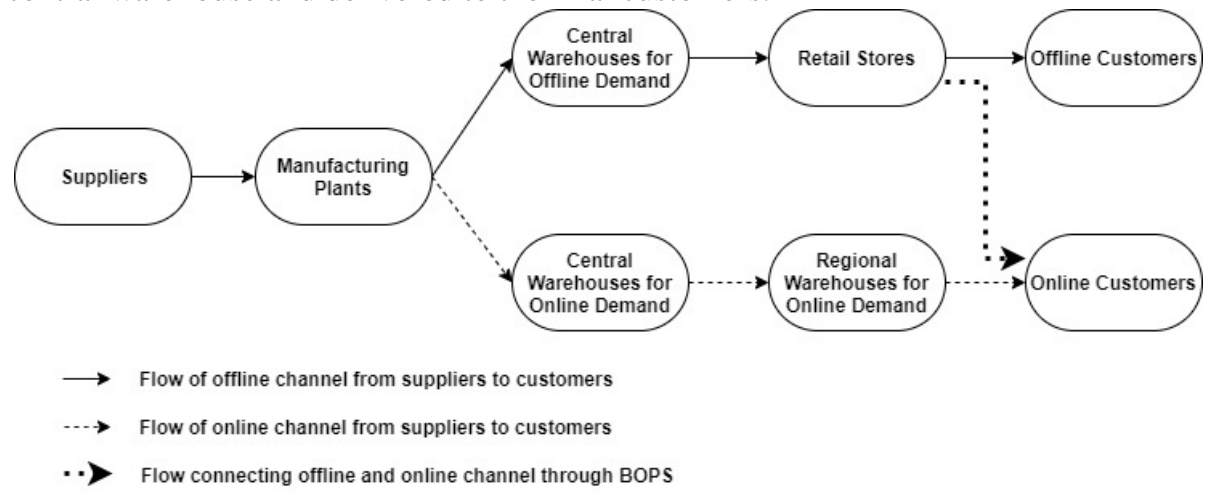

Fig. 1. Supply Chain Network of the Firm.

Based on a detailed analysis of both the online as well as offline customer demands and the associated distribution activities, the firm has realized that the offline and online modes of delivery can be combined to reduce unnecessary extra movement of vehicles. However, this decision should be taken in such a manner that the demands of both the channels are not compromised upon. Based on the deliberation amongst the DMs, the firm has decided to integrate the supply chain of both the modes through BOPS (bold dotted line represented in Fig. 1). It is understood by the firm that this strategic decision can lead to improved productivity through sharing of resources for various activities like inventory holding, transportation, and so on. It will also help in increasing the flexibility of the supply chain as a whole. However, integration of both the channels through BOPS may pose a number of challenges like increased complexity of supply chain, risk of channel conflicts, convoluted inventory, and channel management. These challenges amplify in emerging economies like India due to the presence additional unorganized players in the retail sector. Increase in unpredictability in the customer behavior is a direct off-shoot of these problems in the supply chain. Therefore, the implementation of OC retailing strategies is faced with a lot of uncertainty as it is highly dependent on the customer demands.

It has been recognized by many researchers and practitioners that instead of opening new pickup points for order picking, conversion of retail stores to function as pickup points can be most beneficial for the firm [24]. Some of the reasons for this popular belief are: (i) reduction in the cost of operating separate facilities, (ii) increase in potential cross-selling, (iii) increased store sales, and (iv) impulse buying. Hence, the DMs of the firm have decided that establishment of pickup points for customers must take precedence over other decisions related to the integration of both channels. With due deliberation, it is further acknowledged by the DMs that it may not be beneficial for the firm to adopt an all-inclusive policy, that is, converting all the retail stores to function 
as pickup points. Doing so may lead to demand clashes between the two channels due to limited availability of inventory carrying capacity, unavailability of space, unavailability of workforce, etc. Therefore, the firm needs to first select a fixed number of retail stores from among the existing ones, to function as pickup points.

This forms the base of the problem addressed in this study. The scope of this study is limited to the implementation of OC retailing through BOPS in the National Capital Region (NCR) of India. There are 53 retail stores of the firm in total. Out of these 53 retail stores, after due deliberation among the DMs, the first level of screening was conducted based on criteria like scope of expansion, availability of resources, offline demand, and so on, 46 retail stores were chosen for the second level of evaluation. Therefore, in total 46 retail stores marked in Fig. 2 are considered for expansion as pickup points. The study aims at evaluating all the 46 retail stores based on a number of criteria like online and offline demands, various costs like inventory carrying cost, operational costs; scope of expansion, capacity, accessibility, population characteristics, etc. and then identifying those retail stores which can be converted as pickup points. Thus, to select retail stores for expansion the firm must focus on the following:

- Analyze the geographical customer demand and decide upon how many retail stores must be selected for expansion.

- Identify the criteria for the evaluation of these retail stores for selection by incorporating firm's capabilities, customers' expectations, and customers' characteristics.

- Select the retail stores based on the identified criteria.

The proposed methodology used to help the firm in achieving these objectives is presented in the next section.

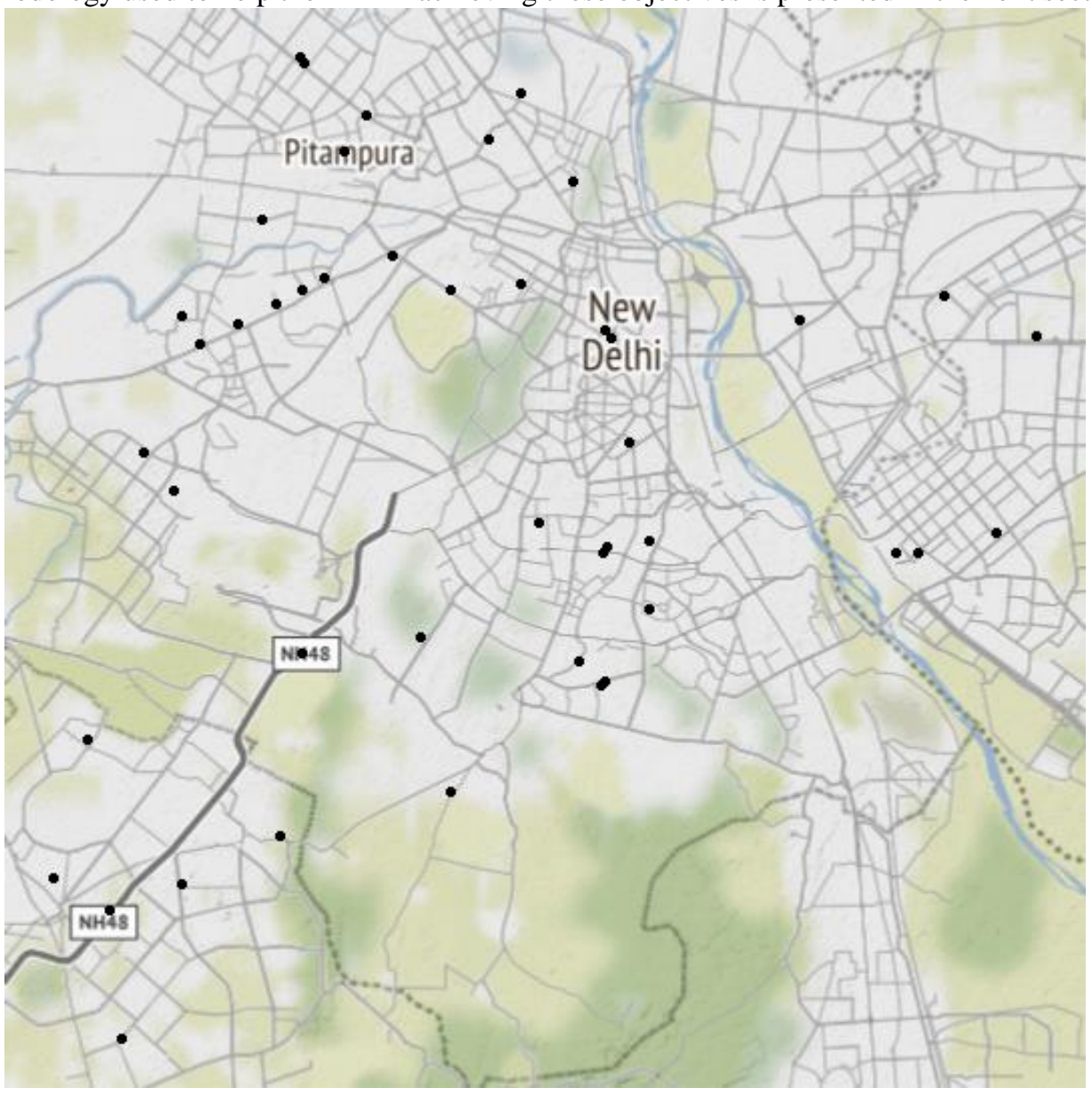

Fig. 2. Store Locations in NCR.

\section{RESEARCH METHODOLOGY}

To help the firm in evaluating and selecting its retail stores for expansion (as pickup points), a three-step framework is developed. The framework is described in detail in this section and is given as follows:

\section{A. Formation of Retail Zones Using K-means Clustering}

Based on the analysis of the geographical customer demand, the firm believes that all the demand can be met smoothly and without much financial burden if 7 retail stores are chosen. To ensure effective demand coverage of the entire NCR, the demand zones are clustered into 7 retail-zones using $K$-means clustering and a retail store from each retail-zone must be selected for expansion. $K$-means clustering is used to develop 7 independent and non-overlapping retail zones of retail stores. It is one of the most widely used partitional clustering algorithm [46], [47]. The latitudinal and longitudinal coordinates of the retail stores are 
utilized for classifying the retail stores into fixed number of retail zones. In $K$-means clustering, the clusters are formed by minimizing the within cluster variance of the observations in each cluster [48]. Given a data set represented by $Y=\left\{y_{1}, y_{2}, \ldots, y_{N}\right\}$ in $R^{M}$, that is the data set consists of $\mathrm{N}$ observations each described by $M$ attributes. With the help of $K$-means clustering, these observations are divided into $K$ exhaustive and mutually exclusive clusters represented by $C=\left\{c_{1}, c_{2}, \ldots, c_{K}\right\}, \cup_{i=1}^{K} c_{i}=Y$ and $c_{i} \cap c_{j}=\phi \forall i, j=1,2, \ldots, K ; i \neq j$. The within cluster variance, the Sum of Squared Error (SSE) is calculated as given in equation (1) [49]:

$$
\operatorname{SSE}=\sum_{i=1}^{K} \sum_{y_{j} \in c_{i}}\left\|y_{j}-a_{i}\right\|_{2}^{2}
$$

where, $\|\cdot\|_{2}$ denotes the Euclidean norm (distance) and $a_{i}=\frac{1}{\left|c_{i}\right|} \sum_{y_{j} \in c_{i}} y_{j}$ is the centroid of cluster $c_{i}$ having $\left|c_{i}\right|$ observations. The objective of $K$-means clustering is to develop clusters such that the SSE is minimized.

The output of $K$-means clustering is highly sensitive to the initial set of centroids used for performing the clustering [50]. If it is not chosen properly, then the algorithm may converge towards a local optimal solution for the objective function. For finding a solution as close to the global optimal solution as possible, initialization methods are used. In this paper, the $K$-means clustering algorithm proposed by [51] is used to cluster the retail stores of the MC retail firm. The steps of which are as follows:

Step 1: Initialization: For initializing the clustering algorithm, the log-linear time complexity initialization algorithm developed by [51] is used. According to this algorithm, the observations in $Y$ are arranged in accordance of their distance from $\bar{Y}$, that is the mean of all the observations. The initial centroid for $i^{\text {th }}$ cluster, $a_{i}^{\prime}$, is the $\left(1+\frac{(i-1) N}{K}\right)^{\text {th }}$ observation.

Step 2: Cluster Assignment: Next the distance of each observation from these $K$ centroids is calculated and the observations are assigned to that cluster whose centroid is closest to them.

Step 3: Centroid Update: New and updated centroids for each cluster are calculated using equation (2)

$$
a_{i}=\frac{1}{\left|c_{i}\right|} \sum_{y_{j} \in c_{i}} y_{j}
$$

Step 4: Iteration: Steps 2 and 3 are iterated to minimize SSE until the cluster assignments stop changing or the maximum number of iterations is reached.

Once the retail zones are made through $K$-means, selection of one retail store for expansion from each zone needs to be done. This is explained in the section that follows.

\section{B. AHP-COPRAS-G Technique for Evaluation and Selection of Retail Stores}

The next step is to evaluate the retail stores on the basis of multiple criteria. The aim is to select one retail store from each retail zone. The integrated AHP-COPRAS-G technique has been utilized for the same. The criteria for evaluation are determined through literature survey and focus group discussions. AHP is used to estimate the importance of each criterion based on judgements of the DMs. COPRAS-G is used to calculate the priority rating of retail stores in each zone. Since, there is uncertainty in the available information related to criteria; therefore, we have used a grey approach for selection. The steps are explained in detail in the following subsections.

\section{1) Identification of criteria for evaluation of retail stores}

There have been many studies regarding multi-criteria analysis for facility selection [52]-[54], however the literature related to retail store location selection problem is limited. Moreover, identification of criteria for evaluation of stores is a crucial process as it depends upon many factors like location characteristics such as accessibility, availability of workforce, attractiveness, and so on along with population characteristics near the retail store such as average monthly income, gender, population size, density of population, and so on [55]-[57]. Recent study by [28] lists a comprehensive list of criteria used by various researchers for store location selection. However, the selection of retail stores for expansion as pickup points must involve a wider range of factors such as store characteristics defined by inventory carrying capacity, workforce productivity, number of checkout counters, etc.; population structure near the retail store defined by percentage of young, population density, etc. Moreover, some additional financial attributes like cost of expansion, hiring cost of staff, etc. also play important role in store evaluation for expansion. Thus, in this paper, post a thorough literature survey, we have selected 18 criteria for retail store expansion through extensive discussions with the DMs. Table I lists down the identified criteria along with their brief description.

TABLE I

EVALUATION CRITERIA

\begin{tabular}{lllc}
\hline \hline Notation & \multicolumn{1}{c}{ Criteria } & Description & References \\
\hline $\mathrm{C} 1$ & $\begin{array}{l}\text { Inventory Carrying } \\
\text { Cost }\end{array}$ & The per unit inventory carrying cost at the retail store & [28], [58]
\end{tabular}




\begin{tabular}{|c|c|}
\hline $\begin{array}{l}\mathrm{C} 2 \\
\mathrm{C} 3\end{array}$ & $\begin{array}{l}\text { Expansion Cost } \\
\text { Labor Charges }\end{array}$ \\
\hline $\mathrm{C} 4$ & Operational Cost \\
\hline $\mathrm{C} 5$ & Workforce Availability \\
\hline C6 & Scope of Expansion \\
\hline $\mathrm{C} 7$ & $\begin{array}{l}\text { Size of Offline } \\
\text { Demand }\end{array}$ \\
\hline $\mathrm{C} 8$ & $\begin{array}{l}\text { Responsiveness to } \\
\text { Customers }\end{array}$ \\
\hline C9 & $\begin{array}{l}\text { Inventory Carrying } \\
\text { Capacity }\end{array}$ \\
\hline $\mathrm{C} 10$ & Ease of Accessibility \\
\hline $\mathrm{C} 11$ & Proximity to Demand \\
\hline $\begin{array}{l}\mathrm{C} 12 \\
\mathrm{C} 13\end{array}$ & $\begin{array}{l}\text { Percentage Elderly } \\
\text { Educational Level }\end{array}$ \\
\hline $\mathrm{C} 14$ & Population Density \\
\hline $\mathrm{C} 15$ & Purchasing Power \\
\hline
\end{tabular}

The per square foot expansion cost of the retail store

The monthly average labor charges at the retail store

The average monthly operational cost of the retail store

The availability of additional workforce at the retail store

The possibility of expansion of the retail store as pick-up point

The average daily traditional demand at the retail store

Responsiveness towards customers' demand which affects the waiting time of the customers

The total inventory carrying capacity of the retail store

The ease of access of the retail store to the customers which includes parking convenience, vehicle traffic density, store visibility, distance to main road, etc.

The average distance that the customers are covering to come to that retail store

The percentage of elderly population amongst the potential customers of the retail store The average educational level of the potential customers of the retail store

The density of population in the neighborhood of the retail store

The purchasing power of the residents of the neighborhood of the retail store
[55], [59]

[28]

[28], [55], [58],

[60]

[61]

[55], [57], [59],

[60]

[28], [58], [60],

[62]

[26]

[13], [25], [57]

[28], [55], [56],

[58], [63]

[28], [56], [60],

[62], [64]

[28], [62]

[28]

[28], [55], [57],

[62]

[28], [55], [57]

Evaluating each of the retail store based on the 18 criteria listed above will be a time-consuming and costly process. Therefore, to simplify the selection process and to make it less time consuming, focus group discussions are conducted with managers and personnel at various retail stores to identify the most critical criteria for evaluating and selecting the retail stores for expansion. Focus group discussions, also known as the process of group interviewing, is an effective qualitative research methodology [65]. A number of structured, semi-structured or unstructured interviews are conducted to study the problem under consideration. It provides the researcher the benefit of interviewing multiple respondents simultaneously and systematically [66].

In this study, the focus group discussions with managers of various retail stores were audio taped and transcribed to allow systematic analysis of the discussions. The duration of discussion was approximately 1 hour and a moderator was responsible for facilitating discussion. The semi-structured questioning approach was adopted by the research team who formulated the questions to be asked during these discussions. The semi-structured format helped in maintaining consistency across multiple groups and also allowed for flexibility in accordance to the topics raised during discussions and the level of participation of each participant. The questions were primarily aimed at assessing the importance of each criteria in evaluating and selecting retail stores for expansion as pickup points considering firms' capabilities, capital investments and customers' expectations. Based on these discussions it was understood that to reduce the number of criteria without losing the essence of each criteria, it would be ideal to group the criteria having high interdependencies and assessing similar characteristics of the store. For instance, criteria like inventory carrying cost, expansion cost, labor charges and operational cost are all inter-related and contribute towards evaluating the financial outcomes so they can be considered together as cost criteria. Similarly, other criteria are also combined as per their inter-relationships to form 5 key criteria for evaluation and selection listed in Table II. The final criteria listed in Table II are used for evaluating and selecting the retail stores for expansion.

TABLE II

FinAL CRITERIA FOR EVALUATION OF RETAIL STORES

\begin{tabular}{lll}
\hline \hline Notation & \multicolumn{1}{c}{ Key Criteria } & \multicolumn{1}{c}{ Includes } \\
\hline KC1 & Cost & C1, C2, C3, C4 \\
KC2 & Expansion Possibility & C6, C7, C9, C16 \\
KC3 & Accessibility & C10, C11 \\
KC4 & Attractiveness & C8, C17, C18 \\
KC5 & Population Characteristics & C5, C12, C13, C14, C15 \\
\hline \hline
\end{tabular}

\section{2) Calculation of criteria weights using AHP}

AHP is a powerful group decision making technique for evaluation of alternatives based on criteria of tangible as well as intangible nature [67, 68]. It is very effective in checking consistency in DMs judgements, as opposed to many other MCDM techniques $[69,70]$. In the present scenario, AHP is ideally suited for evaluation of criteria as the problem structuring associated with developing the pairwise comparison matrices give significant insights into which criterion most influence the location selection decision. The following are the steps of AHP method utilized in this study [67]:

Step 1: Construction of Pair-wise Comparison Matrix: For each DM $(l)$, a pair-wise comparison matrix $P_{l}=\left[p_{u v}^{l}\right]_{n \times n}$ is developed, where $n$ is the total number of criteria to be compared and $p_{u v}^{l}$ represents the pair-wise comparison between criterion $C_{u}$ and criterion $C_{v}$ given by the $l^{\text {th }} \mathrm{DM}$ using a nine-point scale defined by [71] given in Table III. Note that $p_{u v}^{l}=\frac{1}{p_{u v}^{l}} \forall u, v=1,2, \ldots, n$. 


\begin{tabular}{ll}
\hline \hline Intensity of Importance of $C_{u}$ over $C_{v}$ (value of $p_{u v}$ ) & \multicolumn{1}{c}{ Definition } \\
\hline 1 & Equal importance \\
3 & Weak importance \\
5 & Essential or strong importance \\
7 & Demonstrated importance \\
\hline \hline
\end{tabular}

Step 2: Consistency Check of the Judgement Matrices: The consistency of the pair-wise comparison matrix is checked to establish the consistency of judgements of the DMs [68]. For this purpose, Consistency Index (CI) for $l^{t h} \mathrm{DM} C I_{l}$ and Consistency Ratio (CR) for $l^{\text {th }} \mathrm{DM} C R_{l}$ of the pair-wise comparison matrices are calculated as given below:

$C I_{l}=\frac{\lambda_{\max }-n}{n-1} \quad \forall l$

where $\lambda_{\max }^{l}$ is the principal eigenvalue of matrix $P_{l}$ such that $P_{l} \times w_{l}=\lambda_{\max }^{l} \times w_{l}$

and $C R_{l}=\frac{C I_{l}}{R I_{n}} \quad \forall l$

where $R I_{n}$ represents Random Index with respect to $n$ as defined in Table 4.

TABLE IV

RANDOM INDEX (RI) VALUES

\begin{tabular}{clllllllll}
\hline \hline Matrix Size & 1 & 2 & 3 & 4 & 5 & 6 & 7 & 8 & 9 \\
\hline Random Consistency Index & 0.00 & 0.00 & 0.58 & 0.90 & 1.12 & 1.24 & 1.32 & 1.41 & 1.45 \\
\hline \hline
\end{tabular}

The pair-wise comparison matrix $P_{l}$ is said to be consistent when the value of $C R<0.1$.

Step 3: Determining the Average Comparison Matrix: Steps 1 and 2 are repeated for each DM and then an average pair-wise comparison matrix $P$ is formulated by using the geometric means of the pairwise comparison matrices provided by multiple DMs.

Thus, $P=\left[p_{u v}\right]_{n \times n}$ where, $p_{u v}=\left(\prod_{l} p_{u v}^{l}\right)^{1 / l}$.

Step 4: Consistency Check of the Average Judgement Matrix: The consistency of the average judgement matrix $P$ obtained in Step 3 is checked as defined in Step 2.

Step 5: Calculation of Priority Vector: The priority vector w defining the weights of each criterion is calculated by normalizing the geometric mean of the rows of the above matrix $P$.

3) Zone-wise evaluation and selection of retail stores for expansion using COPRAS-G

The final step of the proposed methodology is to evaluate and select the most suitable retail store for expansion in each retail zone using COPRAS-G method [72]. The principal idea behind COPRAS method is to evaluate the alternatives in terms of their significance and degree of utility [73]. The COPRAS-G method is based on the application of grey system given by [74] along with COPRAS method. The idea behind grey system is the uncertainty and availability of incomplete information [75]. Due to unavailability of complete information related to some criteria, we have used COPRAS-G method. The following steps defined by [72] have been used in this paper:

Step 1: Construction of Decision Matrix: In this step a decision matrix $\otimes D=\left[\otimes d_{s u}\right]_{m \times n}$ is constructed where $\otimes d_{s u}=\left[\underline{d}_{s u} ; \bar{d}_{s u}\right] \forall s=1,2, \ldots, m ; u=1,2, \ldots, n$ such that $\underline{d}_{s u}$ is the smallest limit and $\bar{d}_{s u}$ is the highest limit of alternative $s$ with respect to criterion $u$.

Step 2: Normalize the Decision Matrix: In this step the decision matrix obtained in the previous step is normalized using equations (5) and (6) given below:

$$
\begin{gathered}
\tilde{\tilde{d}}_{s u}=\frac{\underline{d}_{s u}}{\frac{1}{2}\left(\sum_{u=1}^{n} \underline{d}_{s u}+\sum_{u=1}^{n} \bar{d}_{s u}\right)}=\frac{2 \underline{d}_{s u}}{\left(\sum_{u=1}^{n} \underline{d}_{s u}+\sum_{u=1}^{n} \bar{d}_{s u}\right)} \\
\tilde{\bar{d}}_{s u}=\frac{\bar{d}_{s u}}{\frac{1}{2}\left(\sum_{u=1}^{n} \underline{d}_{s u}+\sum_{u=1}^{n} \bar{d}_{s u}\right)}=\frac{2 \bar{d}_{s u}}{\left(\sum_{u=1}^{n} \underline{d}_{s u}+\sum_{u=1}^{n} \bar{d}_{s u}\right)}
\end{gathered}
$$

Thus, a normalized decision matrix $\otimes \tilde{D}=\left[\left[\tilde{\tilde{d}}_{s u} ; \tilde{\bar{d}}_{s u}\right]\right]$ is obtained.

Step 3: Formulation of Weighted Normalized Decision Matrix: In this step a weighted normalized decision matrix $\otimes \hat{D}=\left[\left[\underline{\hat{d}}_{s u} ; \hat{\bar{d}}_{s u}\right]\right]$ is constructed as given in (7) and (8) 


$$
\begin{aligned}
& \hat{\hat{d}}_{s u}=\tilde{\tilde{d}}_{s u} \cdot w_{u} \\
& \hat{\bar{d}}_{s u}=\tilde{\bar{d}}_{s u} \cdot w_{u}
\end{aligned}
$$

where $w_{u}$ is the weight of $u^{\text {th }}$ criterion obtained through AHP.

Step 4: Determination of Relative Significance of Each Alternative: For finding out the significance of each alternative, first the sums of the criterion values whose larger values are more preferable are calculated as given in equation (9) below:

$$
P_{s}=\frac{1}{2} \sum_{u=1}^{t}\left(\hat{\underline{d}}_{s u}+\hat{\bar{d}}_{s u}\right)
$$

In equation (9), $t$ is the number of those criteria which are to be maximized.

Similarly, the sums $R_{s}$ of the criterion whose smaller values are preferable are calculated as given in equation (10) below:

$$
R_{s}=\frac{1}{2} \sum_{u=t+1}^{n}\left(\hat{\hat{d}}_{s u}+\hat{\bar{d}}_{s u}\right)
$$

The relative significance of each alternative is calculated as given below in equation (11):

$$
Q_{s}=P_{s}+\frac{\sum_{s=1}^{m} R_{s}}{R_{s} \sum_{s=1}^{m} \frac{1}{R_{s}}}
$$

The alternatives can be selected based on their levels of relative significance.

\section{NUMERICAL VALIDATION}

The methodology discussed in the previous section is applied to the case problem under consideration. This section highlights the findings from its successful implementation.

\section{A. Formation of Retail Zones}

For the construction of retail zones, we have applied $K$-means clustering algorithm $(K=7)$ using 'kmeans' function in $\mathrm{R}$ programming software (version 3.6.1). Fig. 2 shows the locations of 46 retail stores to be grouped into 7 retail zones using $K$ means clustering. The retail zones are formed depending upon the closeness of retail stores, that is, their Euclidean distance from each other. The grouping of retail stores into retail zones helps in increasing the demand coverage and better utilization of resources as the retail stores are spread over the vast area of NCR. Using the latitudinal and longitudinal coordinates corresponding to these retail store locations, the $K$-means algorithm is used to construct 7 retail zones. Table $\mathrm{V}$ lists the retail stores in each of the 7 retail zones constructed through $K$-means algorithm and Fig. 3 illustrates the retail zones thus formed.

$$
\text { TABLE V }
$$

LIST OF RETAIL STORES IN EACH ZONE

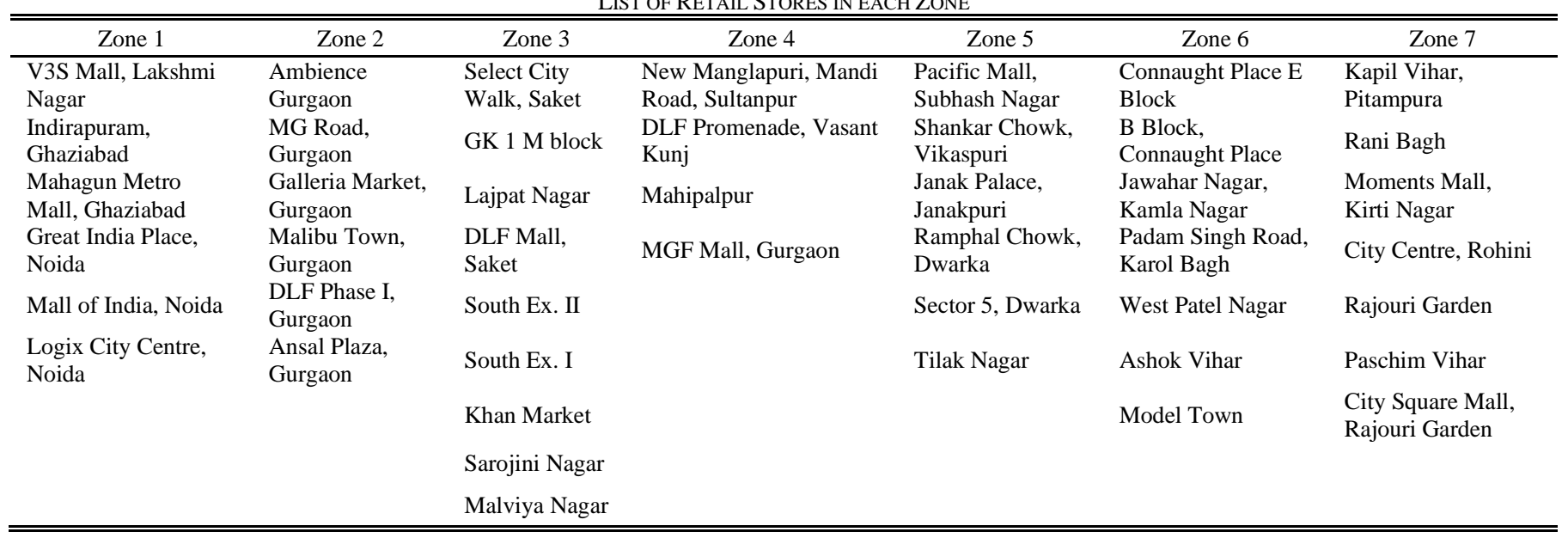




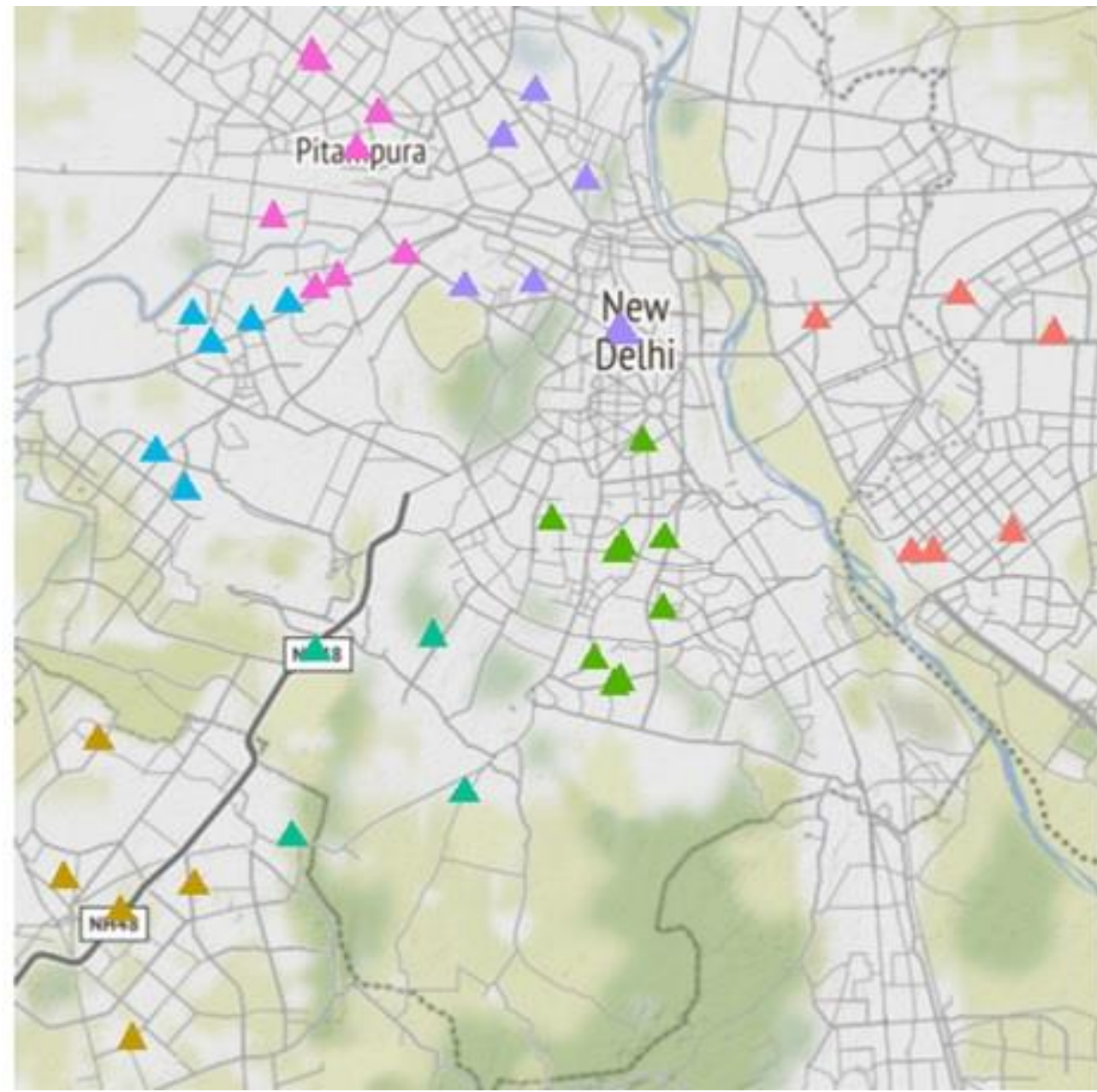

\section{Retail Zones}

Fig. 3. 7 Retail Zones Obtained Through $K$-means Clustering.

\section{B. Evaluation and Selection of Retail Stores for Expansion}

The main objective of the study is to select one retail store for expansion in each of the retail zones. Prior to selection, a twostep evaluation process is conducted. First, the evaluation scores of criteria defined in Table II are determined using AHP, results of which are presented in B.1. Second, the retail stores are evaluated based on the criteria using COPRAS-G. The findings are illustrated in section B.2. For the evaluation process, a team of 6 DMs of the firm is constituted which includes Retail Operations Manager (DM1), Public Relations Manager (DM2), Inventory Control Manager (DM3), Distribution and Logistics Manager (DM4), Finance Manager (DM5) and Information Technology Manager (DM6).

\section{1) Prioritization of criteria of evaluation}

Each of the DMs were asked to fill up a questionnaire and based on their responses, the pair-wise comparison matrices of attributes are formulated. Through the questionnaire, the DMs were asked to provide relative importance ratings of criteria with respect to each other using the scale defined in Table III. Based on their responses, the pair-wise comparison matrices are constructed. For instance, Table VI provides the pair-wise comparison matrix given by DM1. Once the consistency of these matrices have been established, they have been aggregated using geometric mean to determine the aggregate pair-wise comparison matrix of criteria given in Table VII [67]. The aggregate pair-wise comparison matrix was consistent with CR value of 0.026. Using the aggregate pair-wise comparison matrix given in Table VII, the final priority weights of each criterion are calculated as given in Table VIII.

TABLE VI

\begin{tabular}{llllll}
\multicolumn{6}{c}{ PAIR-WISE COMPARISON MATRIX OF DM1 } \\
\hline \hline DM1 & KC1 & KC2 & KC3 & KC4 & KC5 \\
\hline $\mathrm{KC} 1$ & 1 & $1 / 3$ & $1 / 5$ & $1 / 5$ & 7 \\
$\mathrm{KC} 2$ & 3 & 1 & $1 / 3$ & $1 / 3$ & 8 \\
$\mathrm{KC} 3$ & 5 & 3 & 1 & 1 & 9 \\
$\mathrm{KC} 4$ & 5 & 3 & 1 & 1 & 9 \\
$\mathrm{KC} 5$ & $1 / 7$ & $1 / 8$ & $1 / 9$ & $1 / 9$ & 1 \\
\hline \hline
\end{tabular}

TABLE VII 
AGgRegate PAIR-WISE COMPARISON MATRIX

\begin{tabular}{cccccc}
\hline \hline \multicolumn{1}{c}{ KC1 } & KC2 & KC3 & KC4 & KC5 \\
\hline KC1 & 1.0000 & 1.0000 & 0.3684 & 1.0541 & 3.9468 \\
KC2 & 1.0000 & 1.0000 & 0.4155 & 0.5673 & 4.3943 \\
KC3 & 2.7144 & 2.4069 & 1.0000 & 1.6475 & 4.5946 \\
KC4 & 0.9487 & 1.7627 & 0.6070 & 1.0000 & 3.3879 \\
KC5 & 0.2534 & 0.2276 & 0.2176 & 0.2952 & 1.0000 \\
\hline \hline \multicolumn{5}{c}{ TABLE VIII } \\
& FINAL PRIORITY WEIGHTS OF CRITERIA \\
& Criteria & Priority Weights \\
\cline { 2 - 5 } KC1 0.1851 \\
KC2 & 0.1711 \\
KC3 & 0.3708 \\
KC4 & 0.2175 \\
KC5 & 0.0555 \\
\hline \hline
\end{tabular}

Based on the results obtained, it is observed that 'Accessibility' of the retail store to the customers has been considered most important by the DMs. This is due to the fact that for launching BOPS service in its retail stores, convenience of customers is of highest importance for the firm. According to the DMs, if the retail store being expanded as pickup point is not easily accessible to the customers, they will not prefer BOPS option over home delivery of their orders. On the other hand, 'Population Characteristics' is given least importance for evaluation of retail stores for expansion. The reason is that this attribute is of utmost importance in the location selection of setting up of new retail store which been decided upon by the company based on detailed customer survey, however the requirement at present is only to evaluate the existing retail stores for expansion as pick-up points. Based on these weights, each retail store is evaluated next to select the best suitable store for expansion using COPRAS-G.

2) Zone-wise evaluation of retail stores

The evaluation process of the retail stores is based on the judgements of the team of six DMs which are collected through a structured questionnaire. Specifically, for evaluation of stores with regard to the cost criterion, the individual retail store managers are also asked to provide the data. With the help of this data survey, an interval of rating of each retail store based on each qualitative criterion is obtained on a scale of 1 to 6 ; where 1 represents the lowest rating and 6 represents the highest rating and decision matrices are formulated for each retail zone. The normalized decision matrix for the first retail zone is represented in Table IX. The normalized decision matrices are used to formulate weighted decision matrices by using the weights of attributes obtained (Table VIII). The weighted decision matrix for first retail zone is given in Table X. These matrices are utilized to calculate relative significance of retail stores in each zone with respect to the other retail stores in their zone. The relative significance values so obtained are represented in Fig. 4.

TABLE IX

NORMALIZED DECISION MATRIX FOR ZONE 1

\begin{tabular}{cccccc}
\hline \hline & KC1 & KC2 & KC3 & KC4 & KC5 \\
\hline V3S Mall, Lakshmi Nagar & {$[0.1166,0.1215]$} & {$[0.1200,0.1600]$} & {$[0.0741,0.1111]$} & {$[0.1429,0.1786]$} & {$[0.1304,0.1739]$} \\
Indirapuram, Ghaziabad & {$[0.1482,0.1507]$} & {$[0.0800,0.1200]$} & {$[0.1481,0.1852]$} & {$[0.1429,0.1786]$} & {$[0.1304,0.1739]$} \\
Mahagun Metro Mall, Ghaziabad & {$[0.1409,0.1458]$} & {$[0.1600,0.2000]$} & {$[0.1852,0.2222]$} & {$[0.1071,0.1429]$} & {$[0.0870,0.1304]$} \\
Great India Place, Noida & {$[0.1896,0.1944]$} & {$[0.1600,0.2000]$} & {$[0.1852,0.2222]$} & {$[0.1786,0.2143]$} & {$[0.1739,0.2174]$} \\
Mall of India, Noida & {$[0.1944,0.1993]$} & {$[0.2000,0.2400]$} & {$[0.1852,0.2222]$} & {$[0.1786,0.2143]$} & {$[0.2174,0.2609]$} \\
Logix City Center, Noida & {$[0.1968,0.2017]$} & {$[0.1600,0.2000]$} & {$[0.1111,0.1481]$} & {$[0.1429,0.1786]$} & {$[0.1304,0.1739]$} \\
\hline \hline & & TABLE X & & & \\
\hline \hline & WEIGHTED NORMALIZED DECISION MATRIX FOR ZONE 1 & & KC4 & KC5 \\
\hline V3S Mall, Lakshmi Nagar & {$[0.0216,0.0225]$} & {$[0.0205,0.0274]$} & {$[0.0275,0.0412]$} & {$[0.0311,0.0388]$} & {$[0.0072,0.0097]$} \\
Indirapuram, Ghaziabad & {$[0.0274,0.0279]$} & {$[0.0137,0.0205]$} & {$[0.0549,0.0687]$} & {$[0.0311,0.0388]$} & {$[0.0072,0.0097]$} \\
Mahagun Metro Mall, Ghaziabad & {$[0.0261,0.0270]$} & {$[0.0274,0.0342]$} & {$[0.0687,0.0824]$} & {$[0.0233,0.0311]$} & {$[0.0048,0.0072]$} \\
Great India Place, Noida & {$[0.0351,0.0360]$} & {$[0.0274,0.0342]$} & {$[0.0687,0.0824]$} & {$[0.0388,0.0466]$} & {$[0.0097,0.0121]$} \\
Mall of India, Noida & {$[0.0360,0.0369]$} & {$[0.0342,0.0411]$} & {$[0.0687,0.0824]$} & {$[0.0388,0.0466]$} & {$[0.0121,0.0145]$} \\
Logix City Center, Noida & {$[0.0364,0.0373]$} & {$[0.0274,0.0342]$} & {$[0.0412,0.0549]$} & {$[0.0311,0.0388]$} & {$[0.0072,0.0097]$} \\
\hline \hline
\end{tabular}




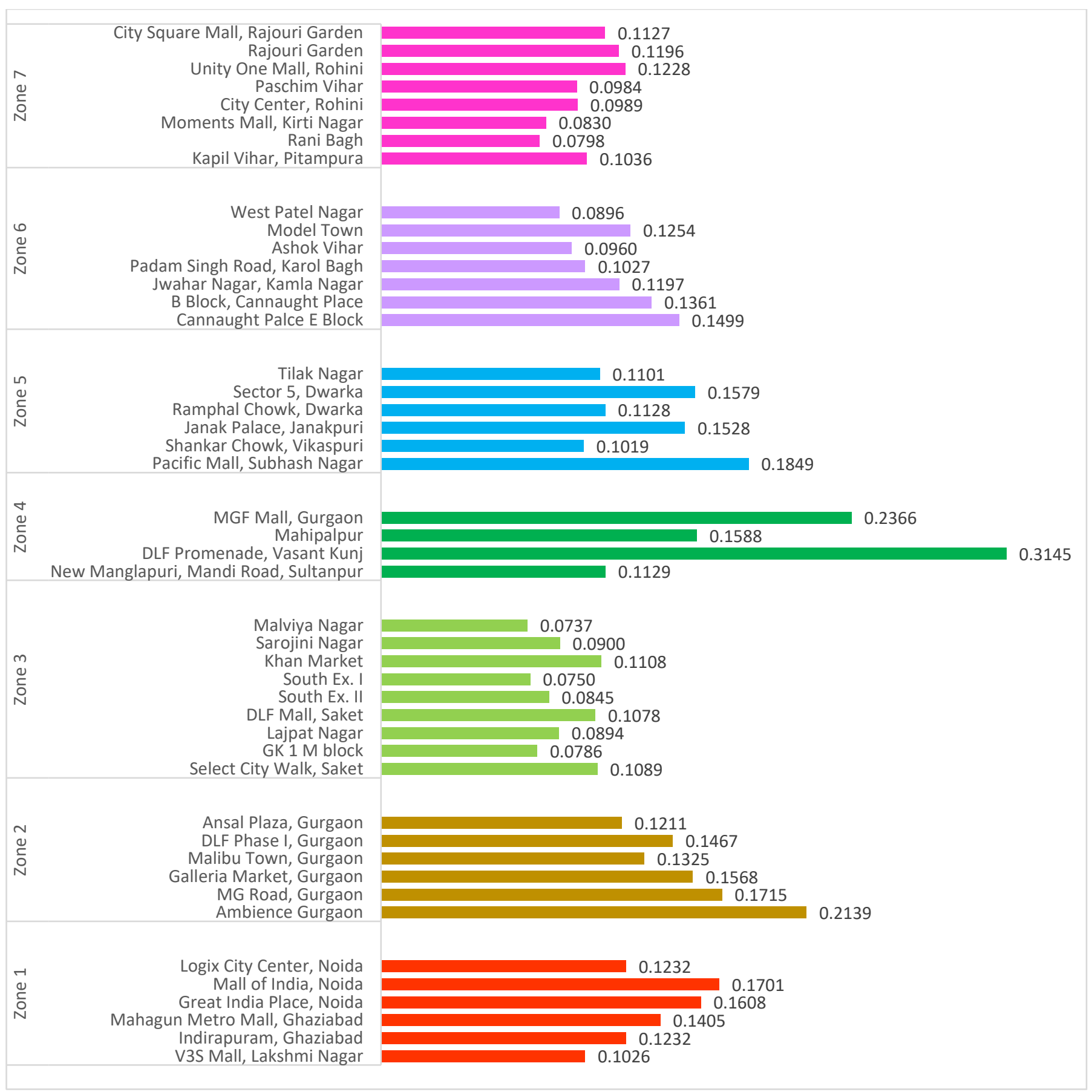

Fig. 4. Relative Significance Values (COPRAS-G) of Retail Stores in each Zone.

As can be seen from Fig. 4, Mall of India, Noida; Pacific Mall, Subhash Nagar; DLF Promenade, Vasant Kunj; Khan Market; Unity One Mall, Rohini; Ambience Gurgaon and Connaught Place E Block have highest relative significance values in their respective clusters. Thus, these 7 retail stores are selected as expansion for functioning as pickup points for BOPS orders along with the traditional offline orders. Fig. 5 represents the selected locations on the geographical map of NCR. The retail store locations marked in blue have been selected for expansion. 


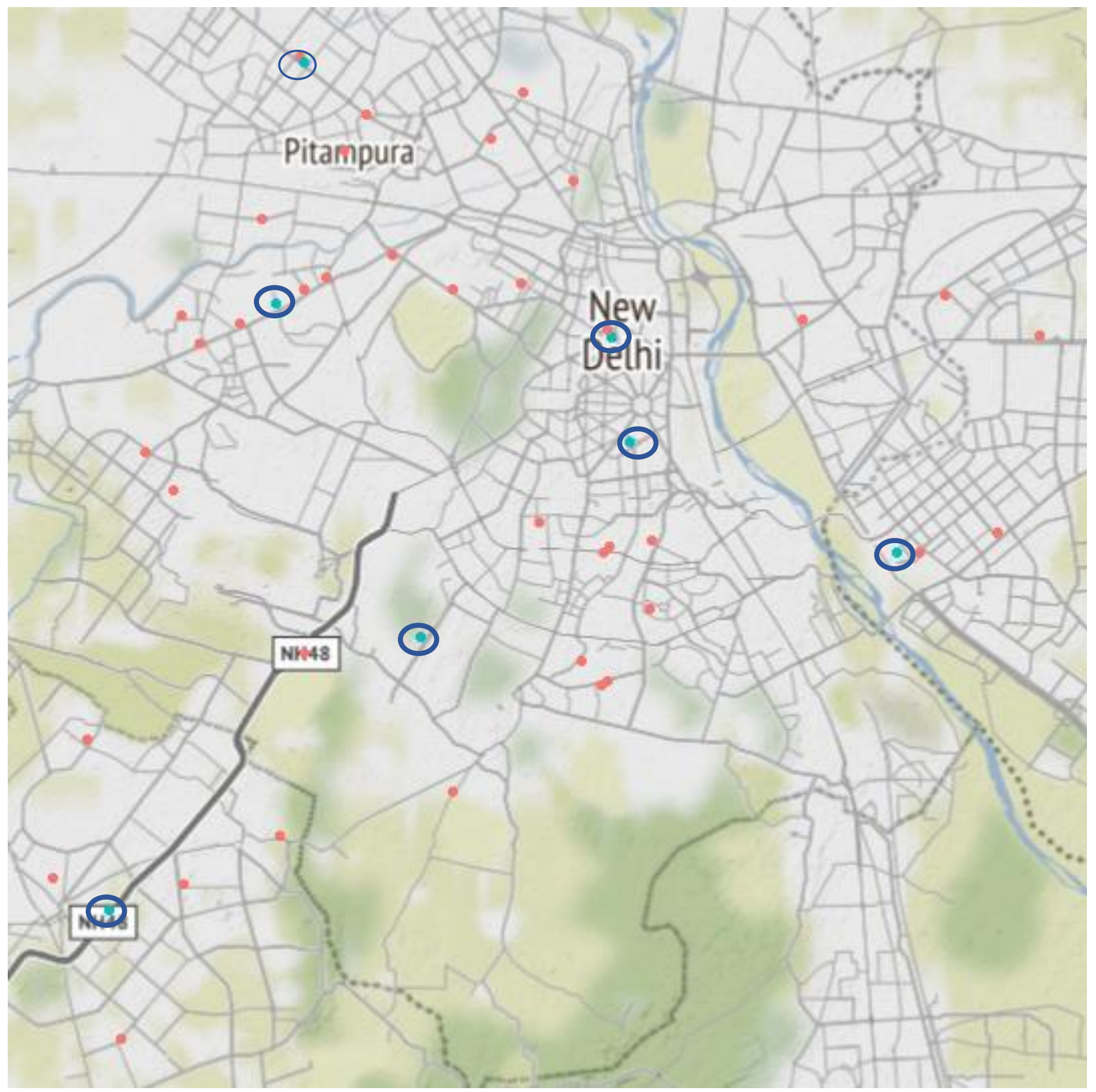

Fig. 5. Retail Store Locations Selected for Expansion.

As can be seen from the results obtained, from Zone 2 retail store located at Pacific Mall, Subhash Nagar has been selected for expansion. Although the cost of operating, expanding and inventory carrying is highest for that location in Zone 5 but it performs exceptionally better on other criteria like expansion possibility and attractiveness. The performance of this store in term of accessibility is also sufficiently well. Whereas, the retail store located at Ramphal Chowk, Dwarka in the same zone has the least cost but does not perform well in terms of other criteria of evaluation. Thus, the retail stores selected within each zone have been selected by achieving a trade-off between the performance of the retail store on the criteria considered for evaluation.

\section{THEORETICAL AND MANAGERIAL IMPLICATIONS}

The study contributes to the growing yet nascent literature related to the adoption of OC retailing and the reconfiguration of supply chain network for the same. This research is valuable to Indian retail firms who want to adopt OC retailing strategy. The research work done may help managers to develop strategic policies in effective implementation of BOPS for achieving significant organizational and competitive advantages. Managers involved in the implementation cannot focus on all organizational aspects simultaneously. They need to first focus on achieving operational efficiency by optimally utilizing the available resources with minimum extra investments. To begin with, selection of retail stores for expansion as pickup points for BOPS orders has been the research scope of the present study. Post selection of retail stores as pick up points, the firm can, at a later stage, focus on designing an effective logistics network. 


\section{A. Theoretical Implications}

Based on the study, the following theoretical implications can be derived:

- OC retailing is already successful in developed nations and India being an emerging economy also has the available environment for such a strategy. Indian retail industry is expected to reach 1.2 billion US\$ by 2021 and the retail sales are at their highest point in the history [76]. The results of the study lead to several implications which can support the firm in appropriate decision making. From the theoretical perspective, this paper provides a framework for Indian retail firms who want to capitalize all possible touchpoints through OC retailing. It can guide retail firms in understanding how BOPS strategy for OC retailing can be implemented in such a manner that maximum demand is satisfied in a costeffective manner.

- The study presents an analytical framework which can significantly benefit the firm's performance in terms of resource utilization, demand fulfilment and customer satisfaction by providing an integrated model for suitable selection of retail stores for expansion as pickup points. This strategic decision making must have hierarchical levels which can be identified based on the firm's objectives like the objective of launching BOPS strategy, the aim of selecting limited number of retail stores, the goal of satisfying maximum demand and so on. In this research, we have achieved these objectives in a step-wise manner.

- The study provides an MCDM framework which can be used to model firm's requirements in terms of goals and criteria for evaluation for practical decision making. The multiple objectives set to achieve for selection of a retail store have been translated in terms of criteria for evaluation of retail stores. Using an MCDM approach, the selection of appropriate retail store is done by obtaining a trade-off between these criteria.

- Also, the study has been conducted in a resource-based view fashion in which the firm's existing resources have been utilized for external opportunities and achieving competitiveness. Considering the aforementioned decision-making outlook, in this study, instead of opening new locations for pickup points of BOPS orders, existing retail stores have been expanded which lead to maximum resource utilization.

\section{B. Managerial Implications}

The study aims to provide the managers of the firm with a thorough understanding of the issues at the strategic level so that an effective implementation of BOPS strategy can be achieved, as discussed below:

- From the practical perspective of BOPS adoption, the study highlights the importance of understanding the market behavior in terms of customer demand and customer accessibility. The extensive research carried on the identification of evaluation criteria allows understanding the significant role of the key factors such as various costs, accessibility, store characteristics and so on in the evaluation of retail stores. Considering various costs while selection allows the managers to focus on economic viability of the decision making. Moreover, evaluation on the basis of accessibility is important as the success of a pickup point highly depends upon its accessibility to the customers. Also, insights about the store characteristics like the number of checkout counters, inventory carrying capacity, availability of workforce, etc. is also important for managers while selecting the retail stores for expansion as it helps them in understanding the practical feasibility of expansion. The results show that the case study firm must focus on these significant criteria to enable a customer-oriented BOPS retail network.

- This assimilation of criteria derives the focus of management towards rating the criteria based on their preferences in such a way that customers' expectations are incorporated appropriately. The ability to model the retail store's performance on a set of criteria considering customers' preferences will offer the firm the capability to maximize customer satisfaction and demand fulfilment.

- Further, the results of the study clearly validate that clustering of retail stores into retail zones based on Euclidean distances and selecting one retail store from each zone for expansion based on its capacity to cater to the customer demand can immensely increase the geographical reach of the firm and increase customer responsiveness. Through this study, the managers can thus effectively plan the logistics network design in the future.

\section{CONCLUSION AND FUtURE RESEARCH}

The paper focuses on strategic implementation of OC retailing strategy for an Indian MC retail firm. The main aim of the study is to help the firm in selecting a fixed number of retail stores for expansion as pickup points. The distinguishing aspects of the proposed study are: (i) a mathematical framework for implementing BOPS strategy of OC retailing for an Indian MC retailing firm has been proposed which guides the MC retail firm in evaluating and selecting a subset of retail stores for expansion, (ii) an exhaustive list of criteria has been chosen through literature review and after due deliberations by the DMs for the evaluation of retail stores with focus on customers' expectations. Through multiple focus group discussions, the large number of identified criteria are grouped based on the interdependencies amongst them and five key evaluation criteria are chosen namely; cost, expansion possibility, accessibility, attractiveness and population characteristics, (iii) an effective integrated MCDM methodology combining $K$-means clustering for construction of retail zones, AHP for deriving importance ratings of the criteria and COPRAS- 
$\mathrm{G}$ for zone-wise evaluation of the retail stores for selection of one retail store per zone has been proposed. Grey system has been used with COPRAS to handle the problem of unavailability of complete information related to some of the criteria.

The case of an Indian apparel MC retail firm has been elaborated in detail to validate the proposed framework. The retail firm had 46 retail stores of which the managers wanted to expand 7 to function as pickup points as well. For this the 46 retail stores were grouped into 7 retail zones using $K$-means clustering. Based on the performance of retail stores in each zone on the criteria under consideration, using AHP-COPRAS-G method, one retail store from each store is selected for expansion. Based on the results obtained, retail stores located at Mall of India, Noida; Pacific Mall, Subhash Nagar; DLF Promenade, Vasant Kunj; Khan Market; Unity One Mall, Rohini; Ambience Gurgaon and Connaught Place E Block have been selected for expansion. The positive outcomes of the proposed mathematical framework are: (i) the formation of the retail zones helps the firm in increasing the demand coverage of the BOPS orders, (ii) the evaluation of retail stores done based on a number of quantitative and qualitative criteria helps in determining the significance of each retail store considering multiple aspects like firm's budget and capabilities along with customers' characteristics and expectations, (iii) managerial insights are drawn related to the strategic decisions that the firm can make for implementing BOPS OC retailing strategy.

The limitations of the study are: (i) the number of retail stores to be expanded as pickup points in the NCR region of India has been fixed by the retail firm based on the demand of offline and BOPS orders and the budgetary restrictions but when the focus area under consideration is increased, other factors like population characteristics, geographical location and so on should also be considered as the number of retail stores to be expanded depends on the characteristics of the region considered for the study; (ii) the criteria for evaluation have been shortlisted by grouping the criteria into a single-criteria to remove strong inter-dependency. It helped in the evaluation process as having large number of criteria makes the evaluation cumbersome and time consuming which leads to increased costs. The grouping of criteria has been done in this study using focus group discussions with various store managers. Techniques like factor analysis, principal component analysis, and so on can be used to make the grouping of criteria more effective; (iii) within the Indian context, the model has been developed for a particular MC retail firm under specific considerations. However, the model can be suitably generalized for other case studies as well. Since, most MC retail firms in India have not yet adopted the OC approach of retailing; therefore, the proposed model will serve as a base for implementation of BOPS strategy by Indian MC retail firms. Moreover, this study focuses only on the selection of retail store for expansion as pickup points, however, how the integration of offline and online channel supply chains can be established has not been explored upon. Such study would involve complexities like managing logistics flows, inventories, overlapping demands, lead times and so on. Considering these limitations, in future a more effective and suitable model can be developed based on the case under study. Moreover, a graph theoretical approach can be used in the future for formation of retail zones which will help in better representation of the geographical separation of the region. Also, the paper does not talk about the risk evaluation of launching such service in the firm's retail stores which is a good research work in the future.

\section{REFERENCES}

[1] G. Li, F. Huang, T. E. Cheng, and P. Ji, "Competition between manufacturer's online customization channel and conventional retailer," IEEE Trans. Eng. Manag., vol. 62, no. 2, pp. 150-157, Mar. 2015.

[2] D. Gao, N. Wang, Z. He, and T. Jia, "The bullwhip effect in an online retail supply chain: a perspective of price-sensitive demand based on the price discount in e-commerce," IEEE Trans. Eng. Manag., vol. 64, no. 2, pp. 134-148, Mar. 2017.

[3] E. Kim, M. C. Park, and J. Lee, "Determinants of the intention to use Buy-Online, Pickup In-Store (BOPS): The moderating effects of situational factors and product type," Telemat. Inform., vol. 34, no. 8, pp. 1721-1735, Dec. 2017.

[4] N. A. Agatz, M. Fleischmann, and J. A. Van Nunen, "E-fulfillment and multi-channel distribution-A review," Eur. J. Oper. Res., vol. 187, no. 2, pp. 339-356, Jun. 2008.

[5] M. Melacini, S. Perotti, M. Rasini, and E. Tappia, "E-fulfilment and distribution in omni-channel retailing: a systematic literature review," Int. J. Phys. Distrib. Logist. Manag., vol. 48, no. 4, pp. 391-414, May 2018.

[6] A. Hübner, A. Holzapfel, and H. Kuhn, "Operations management in multi-channel retailing: an exploratory study," Oper. Manag. Res., vol. 8, no. 3-4, pp. 84-100, Dec. 2015.

[7] J. K. Ryan, D. Sun, and X. Zhao, "Coordinating a supply chain with a manufacturer-owned online channel: A dual channel model under price competition," IEEE Trans. Eng. Manag., vol. 60, no. 2, pp. 247-259, Aug. 2012.

[8] K. Picot-Coupey, E. Huré, and L. Piveteau, "Channel design to enrich customers' shopping experiences: Synchronizing clicks with bricks in an omni-channel perspective-the Direct Optic case," Int. J. Retail Distrib. Manag., vol. 44, no. 3, pp. 336-368, Mar. 2016.

[9] D. Girish, "Omnichannel retail in India: 5 brands that are doing it right," Beaconstac, Mar. 22, 2016. [Online]. Available: https://blog.beaconstac.com/2016/03/omnichannel-retail-in-india-5-brands-that-are-doing-it-right/

[10] A. Hübner, A. Holzapfel, and H. Kuhn, "Distribution systems in omni-channel retailing," Bus. Res., vol. 9, no. 2, pp. 255-296, Aug. 2016.

[11] D. R. Bell, S. Gallino, and A. Moreno, "Offline showrooms in omnichannel retail: Demand and operational benefits," Manag. Sci., vol. 64, no. 4, pp. 1629-1651, Mar. 2017.

[12] D. R. Bell, S. Gallino, and A. Moreno, "How to win in an omnichannel world," MIT Sloan Manag. Rev., vol. 56, no. 1, pp. 45 , Oct. 2014.

[13] Forrester, "Customer desires vs. retailer capabilities: Minding the omni-channel commerce gap," Forrester Consulting Group, Jan. 2014. [Online]. Available:

https://www.accenture.com/us-en/ /media/accenture/conversionassets/dotcom/documents/global/pdf/technology 7/accenture-customer-desires-vs-retailer-capabilities.pdf

[14] F. Gao, and X. Su, “Omnichannel retail operations with buy-online-and-pick-up-in-store,” Manag. Sci., vol. 63, no. 8, pp. 2478-2492, Jun. 2016.

[15] N. T. Balanarayan, "Amazon pilots in-store pick up service in Delhi and Mumbai with BPCL," Medianama, Mar. 18, 2014 [Online]. Available: https://www.medianama.com/2014/03/223-amazon-in-store-pick-up-india-bpcl/

[16] A. Babu, "Flipkart launches 20 pick-up centres to mitigate delivery issues," Business Standard, Jul. 28, 2015. [Online]. Available: https://www.business-standard.com/article/companies/flipkart-launches-20-self-product-pick-up-centres-in-india-115072800762_1.html 
[17] P. Pani, "Supermarket chain DMart pilots delivery, pick-up centres to reach online buyers faster," Business Line, Jan. 13, 2018. [Online]. Avaialble: https://www.thehindubusinessline.com/markets/supermarket-chain-dmart-pilots-delivery-pickup-centres-to-reach-online-buyersfaster/article9560342.ece

[18] R. Bailay, and W. Mukherjee, "Reliance retail has major plans in store for kiranas," The Economic Times, Apr. 19, 2019. [Online]. Available: https://economictimes.indiatimes.com/industry/services/retail/reliance-retail-has-major-plans-in-store-forkiranas/articleshow/68858751.cms?from=mdr\&utm_source=contentofinterest\&utm_medium=text\&utm_campaign=cppst

[19] P. Chatterjee, "Causes and consequences of 'order online pick up in-store' shopping behavior," Int. Rev. Retail, Distrib.. Consum. Res., vol. 20, no. 4, pp. 431-448, Sep. 2010.

[20] S. Gallino, and A. Moreno, "Integration of online and offline channels in retail: The impact of sharing reliable inventory availability information," Manag. Sci., vol. 60, no. 6, pp. 1434-1451, Apr. 2014.

[21] J. Wollenburg, A. Holzapfel, A. Hübner, and H. Kuhn, "Configuring retail fulfillment processes for omni-channel customer steering," Int. J. Electron. Commer., vol. 22, no. 4, pp. 540-575, Oct. 2018.

[22] B. Niu, Z. Mu, and B. Li, "O2O results in traffic congestion reduction and sustainability improvement: Analysis of "Online-to-Store" channel and uniform pricing strategy," Transp. Res. Part E: Logist. Transp. Rev., vol. 122, pp. 481-505, Feb. 2019.

[23] P. Rosenblum, and B. Kilcourse, "Omni-channel 2013: The long road to adoption,” Benchmark Report, RSR Research, Miami, Jun. 11, 2013. [Online]. Available: https://www.rsrresearch.com/research/omni-channel-2013-the-long-road-to-adoption

[24] S. Mahar, P. A. Salzarulo, and P. D. Wright, "Using online pickup site inclusion policies to manage demand in retail/E-tail organizations," Comput. Oper. Res., vol. 39, no. 5, pp. 991-999, May 2012.

[25] B. L. MacCarthy, L. Zhang, and L. Muyldermans, "Best performance frontiers for Buy-Online-Pickup-in-Store order fulfilment," Int. J. Prod. Econ., vol. 211, pp. 251-264, May 2019.

[26] S. Mahar, and P. D. Wright, "In-store pickup and returns for a dual channel retailer," IEEE Trans. Eng. Manag., vol. 64, no. 4, pp. 491-504, Apr. 2017.

[27] C. K. Glaeser, M. Fisher, and X. Su, "Optimal retail location: Empirical methodology and application to practice," Manuf. Serv. Oper. Manag., vol. 21, no. 1, pp. 86-102, Jan. 2019.

[28] G. Turhan, M. Akalın, and C. Zehir, "Literature review on selection criteria of store location based on performance measures," Procedia-Soc. Behav. Sci., vol. 99, pp. 391-402, Nov. 2013.

[29] G. H. Tzeng, and J. J. Huang, Fuzzy Multiple Objective Decision Making. Boca Raton, Florida, USA: CRC Press, 2013.

[30] Y. Ye, K. H. Lau, and L. K. Y. Teo, "Drivers and barriers of omni-channel retailing in China: A case study of the fashion and apparel industry," Int. J. Retail Distrib. Manag., vol. 46, no. 7, pp. 657-689, Jul. 2018.

[31] N. Beck, and D. Rygl, "Categorization of multiple channel retailing in Multi-, Cross-, and Omni-Channel Retailing for retailers and retailing," J. Retail. Consum. Serv., vol. 27, pp. 170-178, Nov. 2015.

[32] J. Lewis, P. Whysall, and C. Foster, "Drivers and technology-related obstacles in moving to multichannel retailing," Int. J. Electron. Commer., vol. 18, no. 4, pp. 43-68, Jul. 2014.

[33] E. Brynjolfsson, Y. J. Hu, and M. S. Rahman, "Competing in the age of omnichannel retailing," MIT Sloan Manag. Rev., vol. 54, no. 4, pp. 1-7, May 2013.

[34] G. M. Fulgoni, ““'Omni-Channel” retail insights and the consumer's path-to-purchase: How digital has transformed the way people make purchasing decisions," J. Advert. Res., vol. 54, no. 4, pp. 377-380, Dec. 2014.

[35] Z. Wang, J. Huang, and B. Tan, "Managing organizational identity in the e-commerce industry: An ambidexterity perspective," Inf. Manag., vol. 50, no. 8, pp. 673-683, Dec. 2013.

[36] O. Rusanen, "Crafting an omnichannel strategy: Identifying sources of competitive advantage and implementation barriers," in Exploring Omnichannel Retailing, W. Piotrowicz, and R. Cuthbertson, Ed., Cham, Switzerland: Springer, 2019, pp. 11-46. [Online]. Available: https://link.springer.com/book/10.1007/978-3-319-98273-1

[37] J. Hagberg, M. Sundstrom, an*d N. Egels-Zandén, "The digitalization of retailing: an exploratory framework," Int. J. Retail Distrib. Manag., vol. 44, no. 7, pp. 694-712, Jul. 2016.

[38] G. Marchet, M. Melacini, S. Perotti, M. Rasini, and E. Tappia, "Logistics in omni-channel retailing: modelling and analysis of three distribution configurations," in 2017 IEEE Int. Conf. Serv. Oper. Logist., Inform. (SOLI), Bari, Italy, 2017, pp. 21-26.

[39] P. Rodríguez-Torrico, R. S. J. Cabezudo, and S. San-Martín, "Tell me what they are like and I will tell you where they buy. An analysis of omnichannel consumer behavior," Comp. Hum. Behav., vol. 68, pp. 465-471, Mar. 2017.

[40] X. Xu, and J. E. Jackson, "Examining customer channel selection intention in the omni-channel retail environment," Int. J. Prod. Econ., vol. 208, pp. 434-445. Feb. 2019.

[41] S. Yan, Z. Hua, and Y. Bian, "Does Retailer Benefit From Implementing "Online-to-Store" Channel in a Competitive Market?," IEEE Trans. Eng. Manag., Nov. 2018.

[42] M. Jin, G. Li, and T. C. E. Cheng, "Buy online and pick up in-store: Design of the service area," Eur. J. Oper. Res., vol. 268, no. 2, pp. 613-623, Jul. 2018.

[43] X. Shi, C. Dong, and T. C. E. Cheng, "Does the buy-online-and-pick-up-in-store strategy with pre-orders benefit a retailer with the consideration of returns?," Int. J. Prod. Econ., vol. 206, pp. 134-145, Dec. 2018.

[44] P. Zhang, Y. He, and X. Zhao, “"Preorder-online, pickup-in-store” strategy for a dual-channel retailer," Transp. Res. Part E: Logist. Transp. Rev., vol. 122, pp. 27-47, Feb. 2019.

[45] M. S. Akturk, M. Ketzenberg, and G. R. Heim, "Assessing impacts of introducing ship-to-store service on sales and returns in omnichannel retailing: A data analytics study," J. Oper. Manag., vol. 61, pp. 15-45, Jul. 2018.

[46] A. K. Jain, M. N. Murty, and P. J. Flynn, "Data clustering: a review,". ACM Comp. Surv. (CSUR), vol. 31, no. 3, pp. $264-323$, Sep. 1999.

[47] A. K. Jain, "Data clustering: 50 years beyond K-means," Pattern Recognit. Lett., vol. 31, no. 8, pp. 651-666, Jun. 2010.

[48] M. S. Yang, and K. P. Sinaga, “A feature-reduction multi-view k-means clustering algorithm,” IEEE Access, vol. 7, pp. 114472-114486, Aug. 2019.

[49] M. E. Celebi, H. A. Kingravi, and P. A. Vela, "A comparative study of efficient initialization methods for the k-means clustering algorithm," Expert Syst. Appl., vol. 40, no. 1, pp. 200-210, Jan. 2013.

[50] G. T. Perim, E. D. Wandekokem, and F. M. Varejão, "K-means initialization methods for improving clustering by simulated annealing," in IberoAmerican Conf. Artif. Intell., Lisbon, Portugal, 2008, pp. 133-142.

[51] J. A. Hartigan, and M. A. Wong, “Algorithm AS 136: A k-means clustering algorithm,” J. R. Stat. Soc.: Ser. C (Appl. Stat.), vol. 28, no. 1, pp. 100-108, Jan. 1979.

[52] L. Chen, J. Olhager, and O. Tang, "Manufacturing facility location and sustainability: A literature review and research agenda," Int. J. Prod. Econ., vol. 149, pp. 154-163, Mar. 2014.

[53] R. Z. Farahani, N. Asgari, N. Heidari, M. Hosseininia, and M. Goh, "Covering problems in facility location: A review," Comp. Ind. Eng., vol. 62, no. 1, pp. 368-407, Feb. 2012 
[54] R. Z. Farahani, M. SteadieSeifi, and N. Asgari, "Multiple criteria facility location problems: A survey," Appl. Math. Model., vol. 34, no. 7, pp. 1689-1709, Jul. 2010.

[55] S. H. Zolfani, M. H. Aghdaie, A. Derakhti, E. K. Zavadskas, and M. H. M. Varzandeh, "Decision making on business issues with foresight perspective; an application of new hybrid MCDM model in shopping mall locating," Expert Sys. Appl., vol. 40, no. 17, pp. 7111-7121, Dec. 2013.

[56] N. Roig-Tierno, A. Baviera-Puig, J. Buitrago-Vera, and F. Mas-Verdu, "The retail site location decision process using GIS and the analytical hierarchy process," Appl. Geogr., vol. 40, pp. 191-198, Jun. 2013.

[57] A. CagriTolga, F. Tuysuz, and C. Kahraman, “A fuzzy multi-criteria decision analysis approach for retail location selection," Int. J. Inf. Technol. Decis. Mak., vol. 12, no. 04, pp. 729-755, Jul. 2013.

[58] S. Önüt, T. Efendigil, and S. S. Kara, "A combined fuzzy MCDM approach for selecting shopping center site: An example from Istanbul, Turkey,” Expert Sys. Appl., vol. 37, no. 3, pp. 1973-1980, Mar. 2010.

[59] J. D. Darbari, V. Agarwal, V. S. Yadavalli, D. Galar, and P. C. Jha, "A multi-objective fuzzy mathematical approach for sustainable reverse supply chain configuration,” J. Transp. Supply Chain Manag., vol. 11, no. 1, pp. 1-12, Feb. 2017.

[60] V. Kumar, and K. Karande, "The effect of retail store environment on retailer performance," J. Bus. Res., vol. 49, no. 2, pp. 167-181, Aug. 2000.

[61] J. D. Darbari, V. Agarwal, and P. C. Jha, "Multi criteria decision making model for optimal selection of recovery facility location and collection routes for a sustainable reverse logistics network under fuzzy environment," in Recent Adv. Math., Stat. Comp. Sci., A. K. Sinha, R. Rajesh, P. Ranjan, R. P. Singh, Ed., Bihar, India, 2016, pp. 29-39.

[62] K. Karande, and J. R. Lombard, "Location strategies of broad-line retailers: an empirical investigation," J. Bus. Res., vol. 58, no. 5, pp. 687-695, May 2005.

[63] A. B. Mendes, and I. H. Themido, “Multi-outlet retail site location assessment," Int. Trans. Oper. Res., vol. 11, no. 1, pp. 1-18, Jan. 2004.

[64] Y. Li, and L. Liu, "Assessing the impact of retail location on store performance: A comparison of Wal-Mart and Kmart stores in Cincinnati," Appl. Geogr., vol. 32, no. 2, pp. 591-600, Mar. 2012.

[65] T. O. Nyumba, K. Wilson, C. J. Derrick, and N. Mukherjee, "The use of focus group discussion methodology: Insights from two decades of application in conservation," Methods Ecol. Evol., vol. 9, no. 1, pp. 20-32, Jan. 2018.

[66] The Basics of Social Research, E. Babbie, eds., 6th ed., Wadsworth Cengage Learning, Belmont, CA, USA, 2014.

[67] M. Bouzon, K. Govindan, C. M. T. Rodriguez, and L. M. Campos, "Identification and analysis of reverse logistics barriers using fuzzy Delphi method and AHP," Resour., Conserv. Recycl., vol. 108, pp. 182-197, Mar. 2016.

[68] F. T. S. Chan, H. K. Chan, H. C. W. Lau, and W. L. I. P. Ralph, "An AHP approach in benchmarking logistics performance of the postal industry," Benchmarking, Int. J., vol. 13, no. 6, pp. 636-661, Nov. 2006.

[69] T. L. Saaty, "Group decision making and the AHP," in The Analytic Hierarchy Process, B. L. Golden, E. A. Wasil, P. T. Harker, eds., Berlin, Heidelberg, Springer, 1989, pp. 59-67. [Online]. Available: https://link.springer.com/book/10.1007/978-3-642-50244-6\#toc

[70] B. Connett, B. M. O'Halloran, and A. G. Pollman, "Advancing the use of an Analytical Hierarchy Process and Improved Random Indexes for making prioritized decisions in systems," IEEE Trans. Eng. Manag., Dec. 2019.

[71] The Analytical Hierarchy Process, T. L. Saaty, eds., McGraw Hill, New York, USA, 1980.

[72] E. K. Zavadskas, A. Kaklauskas, Z. Turskis, and J. Tamošaitiene, "Selection of the effective dwelling house walls by applying attributes values determined at intervals," J. Civ. Eng. Manag., vol. 14, no. 2, pp. 85-93, Jan. 2008.

[73] E. K. Zavadskas, A. Kaklauskas, and V. Sarka, "The new method of multicriteria complex proportional assessment of projects," Technol. Econ. Dev. Econ., vol. 1, no. 3, pp. 131-139, 1994.

[74] J. L. Deng, "Control problems of grey systems," Sys. Contr. Lett., vol. 1, no. 5, pp. 288-294, 1982.

[75] M. Tavana, E. Momeni, N. Rezaeiniya, S. M. Mirhedayatian, and H. Rezaeiniya, "A novel hybrid social media platform selection model using fuzzy ANP and COPRAS-G," Expert Sys. Appl., vol. 40, no. 14, pp. 5694-5702, Oct. 2013.

[76] Indian Retail Industry Report, India Brand Equity Foundation, India. [Online]. Available: https://www.ibef.org/industry/retail-india.aspx 